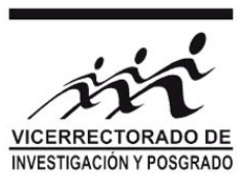

\title{
Editorial: Reflexiones sobre la Ley Universitaria 30220
}

\author{
César Jiménez ${ }^{*}$ \\ ${ }^{1}$ Universidad Nacional Mayor de San Marcos, Lima, Perú
}

Lima, 30 de junio de 2019

\section{Sobre la carrera docente universitaria}

La Nueva Ley Universitaria No. 30220 se promulgó el 08 de julio de 2014, hace 5 años. Según el Artículo 83, para ingresar a la carrera docente (como profesor auxiliar) se requiere Título Profesional, grado de Maestro y 5 años de experiencia profesional. La realidad indica que es poco probable que un profesional (con título, maestría y más de 5 años de experiencia) abandone su actividad laboral para dedicarse a la docencia universitaria como docente auxiliar recibiendo un sueldo de 3658 soles mensuales ( $\sin$ incluir los descuentos de ley), a menos que sea a tiempo parcial. Lo que va a suceder y está sucediendo en algunos procesos de concurso para contratación docente es que las plazas van a quedar desiertas por falta de postulantes o porque estos no cumplen con los requisitos mínimos.

Según la Tercera Disposición Complementaria Transitoria, los catedráticos tienen un plazo de 5 años (a la fecha sólo sería alrededor de un año y medio) para adecuarse a la nueva ley. Esto implica que los actuales docentes auxiliares y asociados titulados (que no obtengan su grado de Maestría, por lo menos) serán cesados, los docentes principales que no tengan el grado de Doctor (con estudios presenciales de 6 semestres académicos como mínimo de acuerdo al Art. 45) pasarán a la categoría de asociados (siempre que tengan el grado de Maestro, caso contrario también serán cesados).

Sobre el límite de edad para la docencia universitaria El Artículo 84 (que ha sido modificado) fija el límite de edad para el ejercicio docente en 75 años, pasados los cuales el docente aún podría continuar ejerciendo la docencia (después de un riguroso concurso de méritos) bajo la modalidad de docente extraordinario (emérito u honorario), pero no podrá ejercer cargo administrativo; es decir, no podrá ser autoridad universitaria. El número de docentes extraordinarios no podrá exceder al $10 \%$ del total, esto significa que habrá un déficit de docentes en algunas Facultades (como la Facultad de Medicina, donde muchos docentes están cercanos al límite de edad). La real experiencia y sabiduría se adquiere con los años dedicados al trabajo e investigación en su respectiva área.

\footnotetext{
*cjimenezt@unmsm.edu.pe
}

La paradoja del catedrático jubilado consiste en que sólo recibirá como pensión de parte del Estado, una fracción de su sueldo activo. Una comparación gruesa sería que el policía más joven ganaría el triple que un catedrático jubilado.

\section{Sobre el Docente Investigador}

El Art. 86 contempla la condición del Docente Investigador, con un bono del $50 \%$ de su haber total y con una carga lectiva de un curso. Sin embargo, esto no se cumple a cabalidad, puesto que el bono sólo se paga de abril a diciembre, pero la investigación es una actividad que se realiza los 12 meses del año, inclusive durante el periodo vacacional. Por lo tanto, el Estado le está robando al Docente Investigador 3 meses de bonificaciones. Tampoco es posible reducir la carga lectiva por falta de docentes.

Sobre las soluciones a los problemas no contemplados Parte de la solución a estos problemas futuros no contemplados por los legisladores (o por los asesores congresales) que diseñaron la Nueva Ley Universitaria, está en la aplicación de una real y efectiva homologación de los haberes universitarios con respecto a los del Poder Judicial (lo que está contemplado en el Artículo 96 de la misma ley) y no en una "homologación" basada en los haberes básicos de los magistrados.

Actualmente, muchos docentes universitarios tienen que dictar en 2 universidades para equilibrar su presupuesto familiar. Solicitar a un docente auxiliar que estudie una maestría donde tendría que pagar una fracción importante de su sueldo mensual, es difícil en las actuales condiciones, a menos que la Universidad respectiva implemente un sistema de semi-becas.

Si se diera una real homologación de los haberes de los catedráticos, en los concursos de ingreso a la docencia universitaria postularían los mejores profesionales e ingresarían los mejores cuadros con un sueldo decoroso que les permitiría disponer de un tiempo para dedicarse a la investigación (que también es uno de los fines de la Universidad Pública) y en pocos años la UNMSM se posicionaría en mejores niveles dentro del ranking de universidades de Latinoamérica y del mundo. 